$(n=1)$. No lead points were found in our 10 patients, although most similar series tend to implicate inverted appendiceal stump, ${ }^{2}$ anastomotic suture line ${ }^{3}$ unrecognised polyp, ${ }^{2}$ hypertrophied lymph nodes, ${ }^{2}$ Meckel's diverticulectomy area, ${ }^{35}$ traumatised intestinal wall. ${ }^{1}$

Once operated on, all infants and children (ours and in other series ${ }^{1-7}$ ) recovered well without an increase in their chances for future recurrent intussusceptions.

\section{References}

1 Brown P M, Thornfeldt R. Intussusception in the early postoperative period. Am J Dis Child 1964; 107: 297-9.

2 Mollitt D L, Ballantine T V N, Grosfeld J L. Postoperative intussusception in infancy and childhood: analysis of 119 cases. Surgery 1979; 86: 402-8.
${ }^{3}$ Dammert G, Votteler T P. Postoperative intussusception in the pediatric patient. J Pediatr Surg 1974; 9: 817-20.

4 Cox J A, Martin L W. Postoperative intussusception. Arch Surg 1973; 106: 263-6.

5 Guttman F M, Ducharme J C, Collin P P. Intussusception after major abdominal operations in children. Can J Surg 1970; 13: 427-33.

6 Hays D M. Intussusception as a postoperative complication in pediatric surgery. Surg Gynecol Obstet 1961; 112: 583-9.

7 Ein S H, Stephens C A. Intussusception: 354 cases in 10 years. J Pediatr Surg 1971; 6: 16-27.

8 Hays D M, Gwinn J L. The changing face in intussusception. JAMA 1966; 195: 817-20.

Correspondence to Dr S H Ein, Suite 315, 250 Lawrence Avenue W, Toronto, Ontario M5M 1B2, Canada.

Received 20 April 1982

\title{
Orocraniodigital (Juberg-Hayward) syndrome with growth hormone deficiency
}

\author{
H M KINGSTON, I A HUGHES, AND P S HARPER \\ Section of Medical Genetics, Department of Medicine, and Department of Child Health, Welsh National \\ School of Medicine, Cardiff
}

SUMMARY A boy is described with Juberg-Hayward syndrome. In addition to unilateral cleft lip and palate, bilateral absent thumbs, anomalous carpal bones, and deformity of the radial heads, there were other skeletal abnormalities. The patient showed clinical and biochemical evidence of growth hormone deficiency which appears to be an integral part of the syndrome.

The orocraniodigital syndrome was first described by Juberg and Hayward ${ }^{1}$ in 1969, affecting 5 children from a sibship of six. The expression of the syndrome was variable in these individuals, the 2 brothers being more severely affected than the 3 sisters. The main features described were unilateral or bilateral cleft lip and palate, hypoplasia and distal displacement of the thumbs, bilateral forearin deformities with anterior displacement of the radial head, anomalous toes, and mild microcephaly. The inheritance appeared to be autosomal recessive with variable expression. The possible sex limitation suggested originally now seems unlikely since the case reported by Nevin et al. ${ }^{2}$ in 1981, in which the patient was a female with full expression of the syndrome. That patient also had additional skeletal abnormalities, notably absence of the pituitary fossa and flattened vertebral bodies. No evidence of endocrine dysfunction was found to account for her short stature.
In this report we describe a boy with features of the orocraniodigital syndrome, who had growth hormone deficiency as well.

\section{Case report}

The patient, a 17-year-old boy, was the only child of healthy unrelated parents. At the time of conception the mother was aged 43 and the father 38 years, neither had oral, cranial, or digital abnormalities and each was of normal intelligence. Their heights were $155 \mathrm{~cm}(-2$ SD) and $160 \mathrm{~cm}$ ( -2 SD). There were no congenital abnormalities in more distant family members. The patient was born at term after a normal pregnancy, with a birthweight of $1.24 \mathrm{~kg}$. Unilateral cleft lip and palate and bilateral absent thumbs were noted at birth. Surgical correction of the cleft lip was carried out at 9 months and of the palate at age 2 years. His progress was satisfactory, apart from short stature and hearing impairment. At age 17 years his height was $143.3 \mathrm{~cm}(-4.7 \mathrm{SD})$, weight $49.4 \mathrm{~kg}$ ( $-2 \mathrm{SD})$, and head circumference $54.4 \mathrm{~cm}(-1 \mathrm{SD})$. Upper to lower segment ratio was $1: 1$. The facies (Fig. 1) showed a prominent forehead with hypoplasia of the mid-face, micrognathia, and repaired unilateral cleft lip and palate. He had a short neck, broad chest, and micropenis. Testes measured $12 \mathrm{ml}$ in volume bilaterally and pubic 
hair was Tanner's stage 4 . The thumbs were bilaterally absent, the left index figure having been pollicised. The left forearm was short and there was incomplete extension at the elbows with restricted supination of the forearms bilaterally. Intellectual function corresponded to the 50th centile on the matrices and the Mill Hill vocabulary scale.

On $x$-ray films the skull and pituitary fossa were normal. There was some flattening of the cervical vertebral bodies with narrowing of $\mathrm{C} 6$ and $\mathrm{C} 7$ disc spaces and spina bifida occulta of the sacral segments. The right 12 th rib was absent. The long bones were of normal shape, except for shortening of the right radius. There was bilateral deformity

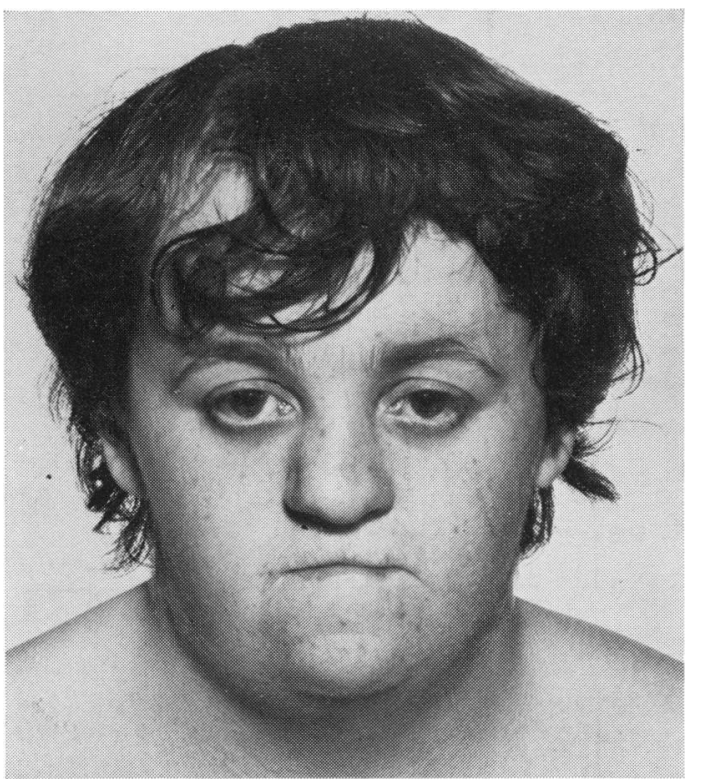

Fig. 1 The patient aged 17 years.

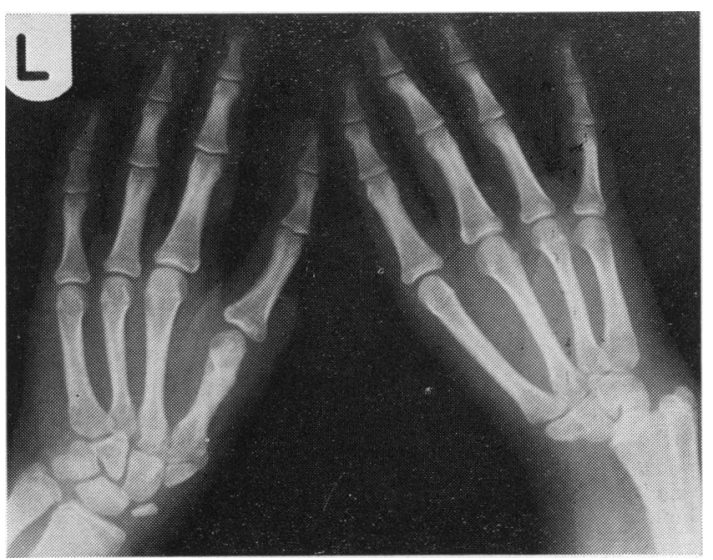

Fig. $2 X$-ray film of hands and wrists. and dislocation of the radial head. The thumbs and first metacarpals were bilaterally absent, with abnormal carpal bones on the radial side of the wrist, associated on the right with subluxation of the carpus (Fig. 2). All metacarpal and phalangeal epiphyses were fused, indicating a skeletal age consistent with chronological age. Intravenous urography showed small rotated kidneys.

Laboratory studies. Chromosome analysis was normal 46XY. Hypothalamic-pituitary function was studied using a standard triple stimulation followed by arginine stimulation test. ${ }^{3}$ The results showed isolated growth hormone deficiency; basal level of $\mathrm{GH}<1.0 \mathrm{mU} / 1$, peak level after stimulation $3.0 \mathrm{mU} / \mathrm{l}$.

\section{Discussion}

The severity and extent of the abnormalities in the orocraniodigital syndrome are variable. The minimum criteria suggested by Juberg ${ }^{4}$ for the diagnosis in an isolated case are unilateral or bilateral cleft lip and palate, anomalous thumbs and toes, and mild microcephaly. In addition to these abnormalities, low birthweight and short stature have been constant findings, while features of a widespread skeletal disorder are more variable, and there may be an associated renal abnormality. ${ }^{12}$ IQ and chromosome analysis appear to be normal.

No endocrine studies were reported in the cases of Juberg and Hayward, ${ }^{1}$ and although the patient of Nevin et al. ${ }^{2}$ had an absent pituitary fossa on skull $x$-rays films, no endocrine abnormality could be found to explain the short stature. Our patient has documented isolated growth hormone deficiency. However, because of his age and skeletal maturation he is likely to achieve limited benefit from growth hormone replacement therapy. Early diagnosis and treatment of growth hormone deficiency in such cases is essential in order to achieve maximum growth potential.

It has been estimated that growth hormone deficiency occurs 40 times more often in short children with cleft lip and palate than in those without. ${ }^{5}$ An embryonal developmental defect is the likely cause of this association, since the lip, palate, and adenohypophysis arise in close proximity. The association of radial defects and cleft lip and palate also appears to be non-random. Kato ${ }^{6}$ in 1924 found orofacial malformations in $2.5 \%$ of cases with radial defects. Any relationship between cleft lip and palate with growth hormone deficiency, or cleft lip and palate with radial defects and the full Juberg-Hayward syndrome requires further elucidation.

In addition to the minimum criteria for the 
diagnosis of the orocraniodigital syndrome, our patient has a more widespread skeletal dysplasia, with absence of thumbs, and isolated growth hormone deficiency. As he is the only child of nonconsanguineous parents, no further information is gained regarding the mode of inheritance.

\section{References}

1 Juberg R C, Hayward J R. A new familial syndrome of oral, cranial, and digital anomalies. J Pediatr 1969; 74: 755-62.

2 Nevin N C, Henry P, Thomas P T S. A case of the orocraniodigital (Juberg-Hayward) syndrome. $\mathrm{J}$ Med Genet $1981 ; 18$ : 478-80.
${ }^{3}$ Savage D C L, Swift P G F, Johnston P G B, Goldie D J, Murphy D. Combined test of anterior pituitary function in children. Arch Dis Child 1978; 53: 301-4.

4 Juberg R C. Oro-cranio-digital syndrome. In: Bergsma D, ed. Birth defects compendium, second edition. New York: Liss, 1979: 828.

5 Rudman D, Davis G T, Priest J H, et al. Prevalence of growth hormone deficiency in children with cleft lip or palate. J Pediatr 1978; 93: 378-2.

6 Kato K. Congenital absence of the radius. $J$ Bone Joint Surg 1924; 6: 589-626.

Correspondence to Dr H M Kingston, Section of Medical Genetics, Department of Medicine, Welsh National School of Medicine, Heath Park, Cardiff CF4 4XN.

Received 27 May 1982

\section{Neonatal rickets in one of identical twins}

\section{Z KOVAR, P MAYNE, AND J WALLIS \\ Department of Child Health and Department of Chemical Pathology, Westminster Medical School and Hospital, London}

SUMMARY We report a case of rickets in one of identical low birthweight twin infants. Plasma 25-hydroxycholecalciferol concentrations were normal in both infants; there was good clinical response to $1-\alpha$ hydroxycholecalciferol. We suggest that there was a delay in maturation of renal 25 -hydroxycholecalciferol-1 $\alpha$ hydroxylase enzyme.

The problem of rickets in the low birthweight infant has been known for some time. ${ }^{1}$ The diagnosis is made on clinical, biochemical, and radiological criteria; serial measurement of plasma alkaline phosphatase activity is useful to screen for disease. ${ }^{2}$ The aetiology of neonatal rickets is multi-factorial. We report a case of rickets in one of identical twins.

\section{Case report}

Female twins (I vertex, II breech) were born at 30 weeks' gestation after a normal pregnancy to a 23-year-old healthy well-nourished white primigravida. The membranes of twin I ruptured spontaneously 36 hours before, and those of twin II at delivery. The placenta weighed $680 \mathrm{~g}$ and was monochorionic and diamniotic. The blood group of both infants was $\mathrm{ORh}^{+}\left(\right.$mother $\left.\mathrm{ARh}^{+}\right)$and identical antigens for the common groups, including Lutheran, Lewis, and Duffy were found. The genotype was $\mathbf{M}+\mathbf{N}+\mathbf{S}-\overline{\mathbf{s}}+\mathbf{P}+\mathbf{L u}^{\mathrm{a}-\mathrm{Le}}(\mathbf{a}-\mathbf{b}+)$ $\mathrm{Fy}^{(\mathbf{a}+\mathbf{b}+)}$ for both children.

Plasma alkaline phosphatase, calcium, and inorganic phosphorus were measured serially from age 2 weeks. ${ }^{2}$ Rickets was diagnosed in twin II at age 6 weeks (36 weeks' post-conceptional age). There was no evidence of rickets in twin I either at this age
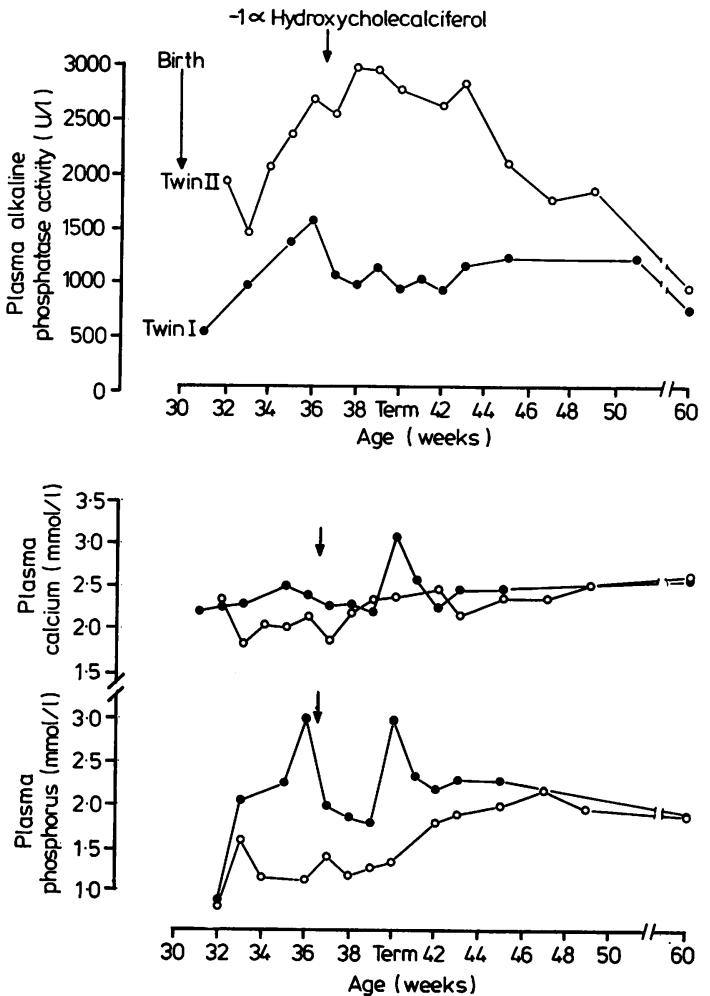

Childhood reference ranges ${ }^{2}$ : Plasma alkaline phosphatase upper limit $850 \mathrm{U} / \mathrm{l}$, plasma calcium $2.20-2.67 \mathrm{mmol} / \mathrm{l}$, plasma inorganic phosphorus $1.02-1.96 \mathrm{mmol} / \mathrm{l}$.

Conversion: SI to traditional units - plasma calcium: $1 \mathrm{mmol} / 1 \approx$ $4.0 \mathrm{mg} / 100 \mathrm{ml}$. Plasma inorganic phosphorus: $1 \mathrm{mmol} / \mathrm{l} \approx 3.0 \mathrm{mg} /$ $100 \mathrm{ml}$.

Figure Serial plasma alkaline phosphatase, calcium, and inorganic phosphorus in both twins. 